\title{
Improving Hydrophobicity of Tropical Hardwood along Axial Positions
}

\author{
${ }^{1 * A D E G O K E, ~ O A ; ~}{ }^{1}$ ADEBAWO, FG; ${ }^{1}$ AJALA, OO; ${ }^{1}$ ADELUSI, EA $;{ }^{2}$ OLOKETUYI, \\ AJ \\ ${ }^{*}$ Department of Wood and Paper Technology, Federal College of Forestry, P. M. B. 5087, Jericho, Ibadan, Nigeria \\ ${ }^{2}$ Department of Forest Conservation \& Protection, Forestry Research Institute of Nigeria, P.M.B. 5054, Jericho, Ibadan, Nigeria \\ *Corresponding Author Email: aolaoluwa.adegoke@gmail.com;adegoke.oa@frin.gov.ng
}

\begin{abstract}
Wood is hygroscopic and is considered dimensionally unstable materials when exposed to wet conditions. To increase the hydrophobicity of wood, this study focused on the modification of tropical hardwood (Triplochiton scleroxylon) along different positions of the stem using acetic anhydride The weight percent gain (WPG) was determined and acetylation reaction was confirmed with FTIR. The dimensional stability of the wood was characterized by water absorption (WA), volumetric swelling (VS), anti-swelling efficiency (ASE), and water repellent efficiency (WRE). Data obtained were subjected to analysis of variance at $\alpha_{0.05}$. It was observed that the weight gain (WG) by acetylation increases along the axial position (base to top) of T. scleroxylon wood. IR-spectra confirmed properly the substitution of the acetyl group. The treatment resulted in a marked improvement in the WA and VS, ASE, and WRE of acetylated T. scleroxylon wood were also found to improve considerably from base to top of the wood. It could be said that the WPG and hydrophobicity increased, but the percentage of water absorption and volumetric swelling diminished. Hence, the modified wood showed good hydrophobicity and improved dimensional stability.
\end{abstract}

\section{DOI:https://dx.doi.org/10.4314/jasem.v25i8.8}

Copyright: Copyright $\left({ }^{\circ} 2021\right.$ Adegoke et al. This is an open access article distributed under the Creative Commons Attribution License (CCL), which permits unrestricted use, distribution, and reproduction in any medium, provided the original work is properly cited.

Dates: Received: 10 May 2021; Revised: 28 June 2021; Accepted: 01 July 2021

Keywords: wood modification, acetylation, hydrophobicity, Triplochiton scleroxylon

Wood is a naturally renewable resource which in general, it's a non-toxic, easily accessible, and inexpensive biomass-derived material. Since ancient times, wood has been used by mankind based on its inherent properties, like any specific part of a tree of particular specie that could be found in the neighborhood was utilized to achieve the best performance when it was used in construction, for different types of tools, or purposes not included in the practical tasks of life. Besides, wood in service is hygroscopic, sensitive to atmospheric humidity changes, and can be subjected to considerable dimensional changes according to its grain directions (Jones and Sandberg, 2020). The sectional cut of wood makes its swelling and shrinkage differ significantly. According to Giordano, 1981, swelling and shrinkage values in the tangential direction are almost twice bigger than those of the radial direction, while in the axial direction these values are inconsiderable. Hence, the dimensional changes that occurred cause splits or deformations. It has becomethe primary interest of scientists to improve the dimensional stability of wood because the variation/change in humidity gives the tendency to swell and shrink thus considered as most negative property. However, several methods have been used to modified wood to improve its dimensional stability likewise its volumetric changes reduction but modification has been provenmore effective (Rowell, 2006, Hill, 2006, Islam et al., 2012, Adebawo et al., 2016). Modification is thus applied to overcome weak points of the wood material that are mainly related to moisture sensitiveness, low dimensional stability, hardness and wear resistance, low resistance to bio-deterioration against fungi, termites, marine borers, and low resistance to UV irradiation (Jones and Sandberg, 2020). Among available modification methods are thermal, resin impregnation, surface modification, and chemical modification (acetylation) which is one of the main methods that reduce the dimensional changes of wood (Rowell, 2006). Acetylation is the most widely used reaction for the chemical modification of wood. It involves the use of, acetic anhydride or acetyl chloride for modifying the chemical structure of the wood (Hill, 2006, Adebawo et al., 2016; Adebawo et al., 2020). Generally, such modification has worked by replacement of the hydrophilic hydroxyls in lignocelluloses with hydrophobic organics, rendering the wood materials water-repellent; consequently, the dimensional stability can be greatly improved. For example, acetylated wood has been found to have a low equilibrated moisture content (EMC) of 2 to $5 \%$ 
and a high anti-swelling efficiency (ASE) of around 70 $\%$, depending on the wood species and treatment conditions (Rowell 2005 and 2006). According to Rowell 1983; Norimoto 2001; Hill 2006; Adebawo et al., 2016, the general principle of chemical wood modification is the reaction of a chemical agent with a functional group (mostly hydroxy groups) of the cell wall polymers and the formation of covalent bonds thus causes a change in the chemical and physical characteristics of wood. Eaton and Hale 1993; Paul and Robert, 2001 reported that with the introduction of bulkier groups within the cell wall, the dimensional stability increases, weathering resistance improves and equilibrium moisture content decreases. Since acetylation could improve the dimensional stability of wood, less work has been done on acetylation of the axial position of Triplichiton scleroxylon wood, T.scleroxylon K. Schum (Obeche) is a high profit, indigenous, non-durable timber species in the Nigerian timber market. This versatile raw material has a huge volume supply, because of its ability to grow under plantation management (Ogunsanwo and Onilude 2000). This study, therefore, teststhe dimensional stability of acetylated wood of Triplichiton scleroxylon (Obeche) along the axial position.

\section{MATERIALS AND METHODS}

Wood Preparation: T. scleroxylonwood was converted into $20 \times 20 \times 60 \mathrm{~mm}$ (radial $\times$ tangential $\times$ longitudinal) wood blocks withno defects. The woodblocks were weighed, then ovendriedat $105 \pm 2{ }^{\circ} \mathrm{C}$ till a constant weight was reached thenrecorded as $\mathrm{W}_{1}$.

Acetylation Procedures: Chemical modification was achieved followingthe methods of (Anne-Marie et al., 1987; Mohebby 2008; Giotra 2009; Adebawo et al., 2016). Wood samples (MC 7\%) were introduced into stainless steel pressure reactor vessels containing the acetylation liquid, (i.e., acetic anhydrideand acetic acid (92:8)). To achieve pre-impregnationof the wood with the reagent, the temperaturewas set at $25^{\circ} \mathrm{C}$ and $10-15$ bar for 30 minutes Then, the reaction temperature was set at $120{ }^{\circ} \mathrm{C}$ for $0,60-, 120-, 180-$, 240- and 300 minutes with 20 wood blocks per period of exposure. After the acetylation reaction, the reactor was cooled in an ice bath. The wood samples were extracted and washed several times to remove excess acetic anhydride andthe by-product (i.e. acetic acid) until no acid smell was detected at pH 7.4. The wood samples were air-dried andthen oven-dried at $105 \pm 2$ ${ }^{\circ} \mathrm{C}$ for $24 \mathrm{~h}$, the weight was recordedas $\mathrm{W}_{2}$. The weight gain (WG) and volume gain (VG) were calculated using Eqn.(1).
$W P G(\%)=\frac{W_{2}-W_{1}}{W_{1}} \times 100$

Where, WPG = weight percent gain; $\mathrm{W}_{1}=$ oven - dry weight of samples before treatment $(\mathrm{g})$;

$\mathrm{W}_{2}=$ oven-dry weight of samples after treatment $(\mathrm{g})$

Dimensional Stability:Anti-swell efficiency (ASE) and water repellent efficiency (WRE) for both modified and unmodified samples were measured according to ASTM -1037 (1999). Five oven-dry specimens for each treatment with dimensions $(20 \mathrm{X}$ $20 \mathrm{X} 10 \mathrm{~mm}$ ) were soaked in a water bath at a temperature of $20 \pm 1{ }^{\circ} \mathrm{C}$ for $168 \mathrm{~h}$; the weight and dimension of specimens were determined before and after soaking.

$W A(\%)=\frac{W-W_{1}}{W_{1}} X 100$

Where, WA= water absorption; $\mathrm{W}_{2}=$ weight of specimen after water soaking, $\mathrm{W}_{1}=$ weight of specimen before water soaking.

$V S(\%)=\frac{V_{2}-V_{1}}{V_{1}} \times 100$

Where, VS= volumetric swelling; $\mathrm{V}_{1}=$ volume of wood before soaking, $\mathrm{V}_{2}=$ volume of wood after soaking

Anti-swell efficiency was calculated according to Eqn. (3) and (4)

$\operatorname{ASE}(\%)=\left(\frac{S_{u}-S_{m}}{S_{u}}\right) \times 100$

Where, ASE $=$ anti-swell efficiency, $\mathrm{S}_{\mathrm{u}}=$ volumetric swelling coefficient of unmodified wood samples, $\mathrm{S}_{\mathrm{m}}=$ volumetric swelling coefficient of modified wood samples

Water repellent efficiency was calculated according to Eqn. (2) and (5)

$W R E(\%)=\left(\frac{W_{u}-W_{m}}{W_{u}}\right) \times 100$

where, $\mathrm{W}_{\mathrm{u}}=$ water absorption of unmodified samples, $\mathrm{W}_{\mathrm{m}}=$ water absorption of modified samples.

FT-IR Analysis:The acetylated and unmodified samples were ground in a Wiley Mill machine and sieved to 40-mesh particle size. Extractives-free wood samples were prepared using acetone and hot water following a standard method (TAPPI T264 CM97, Oct.2007) for FT-IR spectrophotometry. The IR spectra of the acetylated and unmodified samples were 
obtained using an ATR technique using a PerkinElmer FT-IR Frontier spectrophotometer by the accumulation of 64 scans with a resolution of $4 \mathrm{~cm}^{-1}$ at $600-4000 \mathrm{~cm}^{-1}$.

Statistical analysis: Data obtained were analyzed using analysis ofvariance (ANOVA). Acetylated and unmodified means were separated using theDuncan multiple range test at $\alpha_{0.05}$.

\section{RESULTS AND DISCUSSIONS}

Weight percent Gain (WPG) of Acetylated Triplochiton scleroxylon Wood:The results for the percentage of weight gainare graphed in Fig. 1. The WPG along the axial positions (top-base) also ranged between $18.16-17.58 \%$ while the highest and lowest recorded at the top and base of the wood respectively hence an increase in weight gains along the axial direction of sampled wood. However, the WPG indicates the chemical reaction that occurred inside the cell wall rather than just within the cell lumen. A higher WPG at the top positions shows that there is a relationship between the mass and WPG of the wood species. The results have shown that WPG is dependent on the mass of the wood species. Thus, lower density wood at the top position gains higher amounts of acetyl groups (Mohebby and Hadjhassani, 2005; Islam et al., 2012, Shi et al., 2013; Adebawo et.al., 2016; Adebawo et al., 2020).

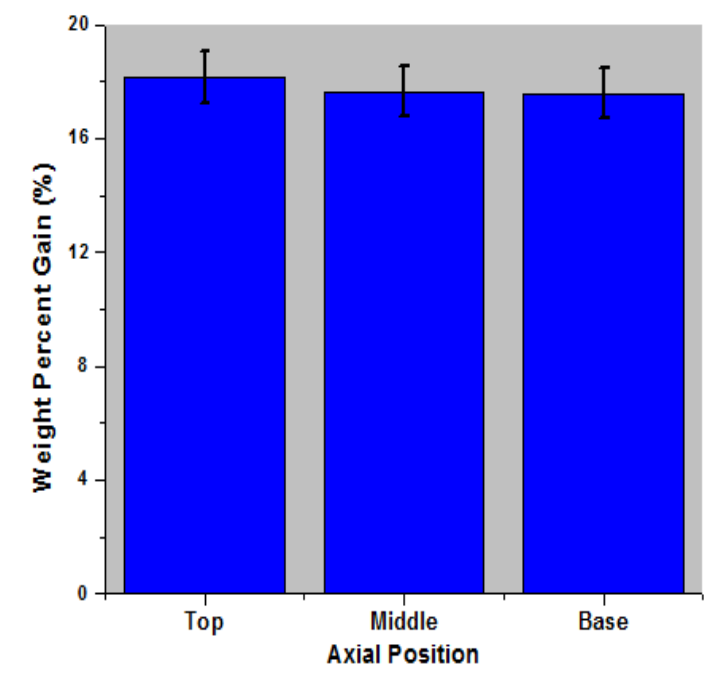

Fig 1: Weight percent gain of acetylated T.scleroxylon wood as a function of axial positioning

FTIR Analysis: The IR spectroscopy was used to confirm the esterification of the hydroxyl group in wood and acetic anhydride as graphed in Fig. 2 which also observed the increase in the number of acetyl groups. Three major strong peaks were observed in the acetylated samples when compared to the unmodified (controls). The relevant peaks are carbonyl $(\mathrm{C}=\mathrm{O})$ stretch region, carbon-hydrogen $(\mathrm{C}-\mathrm{H})$ bond, and carbon-oxygen (C-O) stretch which occurred at $\left(1738-1730 \mathrm{~cm}^{-1}\right), 1375-1370 \mathrm{~cm}^{-1}$, and (1243-1000 $\mathrm{cm}^{-1}$ ) respectively (Rowell 2012; Hon, 1996; Matsuda. 1996). Meanwhile, the strong band of the carbonyl group at $1738-1730 \mathrm{~cm}^{-1}$ in all of the treated samples except unmodified wood strongly suggested that hydroxyl functional groups $(-\mathrm{OH})$ in the $T$. scleroxylon wood along axial position were acetylated. Also, the appearance of the peak at $1370 \mathrm{~cm}^{-1}$ in acetylated wood could indicate $\mathrm{C}-\mathrm{H}$ vibrations in cellulose and hemicelluloses from the methyl group (of the acetyl unit) Evans et al., 1992; Sundell et al., 2001. The presence of a chemical group assigned to 1245-1000 $\mathrm{cm}^{-1}$ indicates $\mathrm{C}-\mathrm{O}$ stretch and due to carbonyl deformation in the ester bond in lignin and xylan during the acetylation (Sundell et al., 2001; Moheeby, 2008; Beaudoin et al., 1992). The spectra obtained also showed that acetylated samples had a higher IR transmission than the control (Fig. 2). Convincingly, IR-spectra confirmed properly the substitution of the acetyl group.

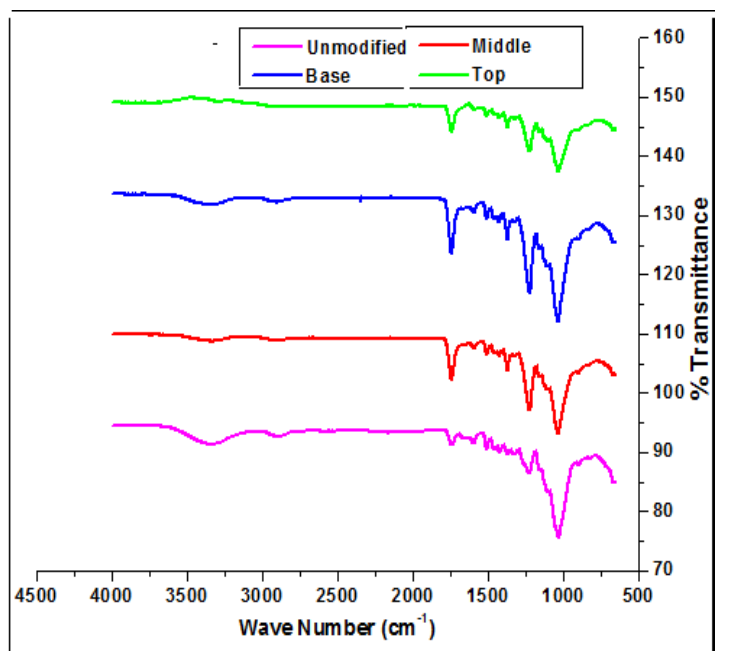

Fig 2: IR-Spectra of the acetylated $T$. scleroxylon wood along axial position

Estimation of Dimensional Stability: The results of volumetric swelling (VS), anti-swell efficiency (ASE) water absorption (WS), and water repellent efficiency (WRE) of acetylated and untreated (control) $T$. scleroxylon wood are graphed in Fig. 3 and 4 respectively. The VS decreases from top to base with an increase ASE from top to base linearly with a decrease in WG from top to base. Meanwhile, WA follows the same pattern of decrease from top to base while an increase in WRE along with the axial position. The result follows a linear direction for all the swelling properties (VS, ASE, WRE, and WA) tested. The average VS ranged between 3.51 and 3.2 
$\%$ with decrease and increase order from top to base and base to top respectively while unmodified (control) had the highest VS of $12.81 \%$. ASE also follows an increase and decrease order from top to base and base to top with 72.49, 73.07, and 75.00\%. The average WA and WRE for acetylated wood of $T$. scleroxylon at the top, middle, and base were 188.58, $125.14,91.72 \%$, and $71.38,105.64,122.93 \%$ respectively. The pattern of decrease and increase from top to base and base to the top follows a linear direction. Analysis of variance conducted shows that a significant difference $(\mathrm{p} \leq 0.05)$ existed between axial position and days after soaking for VS, ASE, WA, and WRE (Table 1). This implies that the acetylation decreased moisture absorption in the wood as the days of soaking increases.

Table 1:Various F.Cal. of hydrophobicity test for acetylated T. scleroxylon wood

\begin{tabular}{|c|c|c|c|c|c|c|c|c|}
\hline \multirow{3}{*}{$\begin{array}{l}\text { Source of } \\
\text { Variation }\end{array}$} & \multicolumn{8}{|c|}{ Hydrophobicity Test (\%) } \\
\hline & \multicolumn{2}{|l|}{$\begin{array}{l}\text { Volumetric } \\
\text { Swelling }\end{array}$} & \multicolumn{2}{|c|}{$\begin{array}{l}\text { Anti-swell } \\
\text { Efficiency }\end{array}$} & \multirow{2}{*}{$\begin{array}{l}\text { Water } \\
\text { Absorption } \\
\text { F-Cal. } \\
\end{array}$} & \multicolumn{3}{|c|}{ Water Repellent Efficiency } \\
\hline & F-Cal. & Sig. & F-Cal. & Sig. & & Sig. & F-Cal. & Sig. \\
\hline $\begin{array}{l}\text { Days After } \\
\text { Soaking (DAS) }\end{array}$ & $23584.78^{*}$ & 0.00 & $1.95 \mathrm{~ns}$ & 0.16 & $326873967 *$ & 0.00 & $114.52 *$ & 0.00 \\
\hline Axial Position (AP) & $6583995.13^{*}$ & 0.00 & $4.31 *$ & 0.03 & $1179893647^{*}$ & 0.00 & $62.49 *$ & 0.00 \\
\hline DAS * AP & $7879.41 *$ & 0.00 & $3.60 *$ & 0.02 & $10897252.70 *$ & 0.00 & $0.916 \mathrm{~ns}$ & 0.50 \\
\hline
\end{tabular}

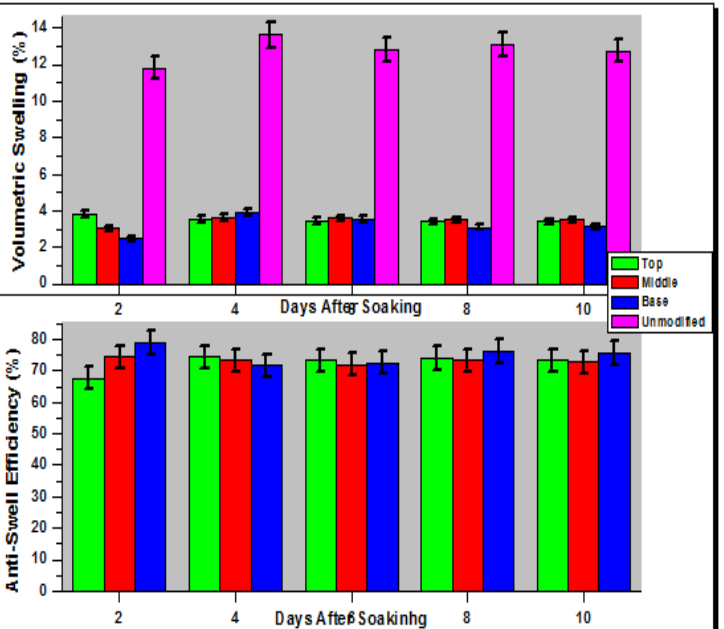

Fig 3: Volumetric swelling and anti-swell efficiency of acetylated T. scleroxylonwood

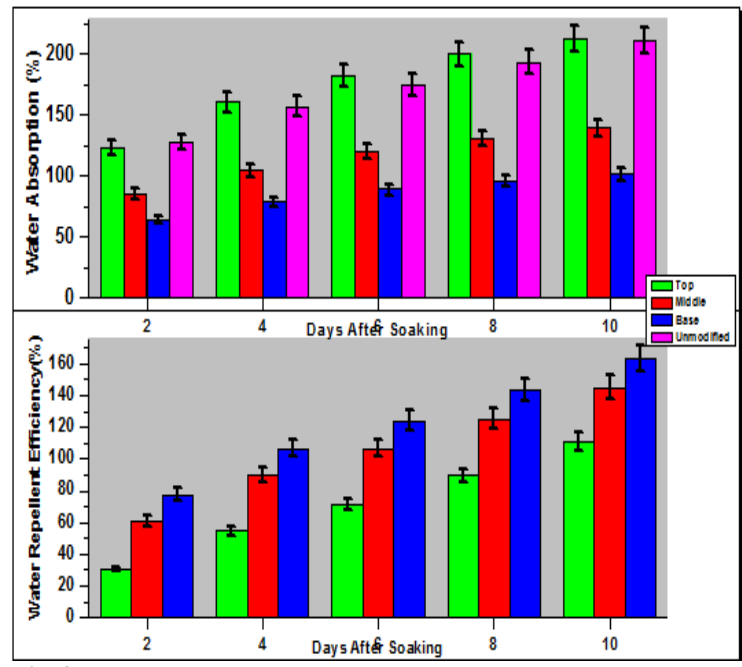

Fig 4: Water absorption and water repellent efficiency of acetylated $T$. scleroxylonwood
The result obtained so far gives evidence that acetylation has a favorable effect on the water absorption and volumetric swelling of the wood. Furthermore, at the possible increase in acetylation time, WPG will increase naturally hence no more increase in WA and VS because the hydroxyl groups in the wood are replaced by acetyl groups, thus reducing the rate at which the wood absorbs water and swells, Fig 3\&4. In addition, Li et al., 2000; Rowell and Eillis, 1978 also reported that during acetylation, the wood is nearly swelled to its original volume due to the replacement of the $(-\mathrm{OH})$ groups with acetyl groups which leads to an increase in wood volume proportional to weight gain. The acetylated $T$. scleroxylon wood along axial position thus dimensional stability when compared to the control since there was a slight increase in weight due to the swollen state of the cell wall and thus making it difficult for the acetylated wood to absorb water further (Rowell et al., 2009; Adebawo et al., 2016).

Conclusion: The acetylation of Triplochiton scleroxylon wood at different axial positions gave different WPG values. The result of FT-IR confirmed the substitution of the hydroxyl groups by acetyl groups. The treatment improved the hydrophobicity of the wood samples which is seen in the significant increase of ASE and WRE irrespective of the axial position when compared to the untreated samples (unmodified samples). This has confirmed that better dimensional stability of the wood species could be obtained using acetylation reaction.

\section{REFERENCE}


Adebawo, FG; Ogunsanwo, OY; Olajuyigbe, SO (2020). Decay Resistance of the Acetylated Tropical Hardwood Species. J For Environ Sci 36(3):225-232.

Adebawo, FG; Naithani, V; Sadeghifar, H; Tilotta, D; Lucia, LA; Jameela, H; Ogunsanwo, OY (2016). Morphological and interfacial properties ofchemically modified tropical hardwood.RSC Adv. DOI: $10.1039 / \mathrm{c} 5 \mathrm{ra19409a}$

Anne-Marie, T; Rune, S; and Rowell, RM; (1987). Dimensional stability and resistance to biological degradation of wood products by a simplified acetylation procedure. In: Proceedings, 4th International Symposium of Wood and Pulping Chemistry; Paris, France; April 27-30, 1987. pp 125129.

ASTM D1037 (1999). Standard test methods for evaluating properties of wood-based fiber and particle panel materials, Philadelphia, PA: American Society for Testing and Material, 1999.

Beaudoin M; Hernandez RE; Koubaa A; Poliquin J (1992) Interclonal, intraclonal and within-tree variation in wood density of poplar hybrid clones. Wood Fiber Sci 24(2):147-153.

Eaton, RA; Hale, MDC (1993). Wood: Decay, Pests, and Protection. Chapman \& Hall, London, 546 pp.

Evans, PD; Michell, AJ; Schmalzl, KJ (1992). Studies of the degradation and protection of wood surfaces. Wood Sci. Technol. 26: 151-163

Girotra, K (2009). Process for Wood Acetylation and ProductThereof. WO2009095687

Hill, CAS (2006). Wood modification - chemical, thermal and other processes. Wiley Series in Renewable Resources,Wiley and Sons, Chichester, UK, pp. 260.

Hon, D (1996). Chemical Modification of Solid Wood, CRC Press,pp. 1-370, ISBN: 0824794729.

Islam, S; Hamdan, S; Rusop, M; Rahman, R; Ahmed, AS;Mohd Idrus, MAA (2012). "Dimensional Stability and Water Repellent Efficiency Measurement of Chemically Modified Tropical Light Hardwood. BioResources 7(1):1221-1231.

Jones, D; Sandberg, D. (2020). A Review of Wood Modification Globally - Updated Findings from COST FP1407 Interdisciplinary perspectives on the built environment, $1 ; 31$.

Li, J; Takeshi, F; Sadanobu, K; Tohru, U (2000). Chemical modification of wood by anhydrides without solvents or catalysts. J.Wood Sci.,46:215221.

Matsuda, H (1996). Chemical modification of lignocellulosic materials, ed. D. N. S. Hon, Marcel Dekker, Inc., New York, Basel, Hong Kong, pp. 159183.

Mohebby, B (2008). Application of ATR Infrared Spectroscopy in Wood Acetylation. J Agric Sci Technol 10: 253-259.

Mohebby, B; Hadjhassani, R (2005). Water repellent effect of the acetylation of poplar fibres. The second European conference on wood modification. Ed. HolgeMilitz and Callum Hill. Pp138-144

Norimoto, M (2001). Chemical modification of wood. In: Wood and cellulosic chemistry (Hon DNS, Shiraishi N, eds). 2nd ed. Marcel Dekker, New York, pp 573598.

Ogunsanwo, OY; Onilude, MA (2000). Specific gravity and shrinkage variation in plantation grown obeche (Triplochiton scleroxylon K. Schum). J Trop For Res 16: 39-45.

Rowell, RM; Ellis, WD (1978). "Determination of dimensional stabilization of wood using the watersoak method," Wood and Fiber Science 10(2), 104111 .

Rowell, RM (1983). Chemical modification of wood: A review. Commonwealth Forestry Bureau, Oxford, England, 6(12), 363-382.

Rowell, RM (2005). "Chemical modification of wood" Handbook of Wood Chemistry and Wood Composites, CRC Press LLC, 381-420.

Rowell, RM (2006). Acetylation of wood: A journey from analytical technique to commercial reality, Forest Products Journal, 56(9): 4-12.

Rowell, RM; Ibach, RE; McSweeny, J; Nilsson, T (2009). Understanding decay resistance, dimensional stability and strength changes in heat-treated and acetylated wood, Wood Materials and Engineering, 1-2:14-22.

Rowell, R (2012). Chemical Modification of Wood to Produce Stable and Durable Composites. Cellul Chem Technol 46: 443-448.

Shi, Z; Fu, F; Wang, S; He, S; Yang, R (2013). Modification of Chinese Fir with Alkyl Ketene Dimer (AKD): Processing and Characterization. BioResources 8 (1):581-591.

Sundell, P; de Meijer, M; Militz, H; van Veldhuizen, B (2001). Influence of chemical modification on the stability of lignin. BioRes. 9 (7):522-531. 